\title{
HIGH-QUALITY SURFACE PASSIVATION OBTAINED BY HIGH-RATE DEPOSITED SILICON NITRIDE, SILICON DIOXIDE AND AMORPHOUS SILICON USING THE VERSATILE EXPANDING THERMAL PLASMA TECHNIQUE
}

\author{
B. Hoex ${ }^{1,2}$, F.J.J. Peeters ${ }^{1}$, A.J.M van Erven ${ }^{2}$, M.D. Bijker ${ }^{2}$, W.M.M. Kessels ${ }^{1}$, M.C.M. van de Sanden ${ }^{1}$ \\ Department of Applied Physics, Eindhoven University of Technology, P.O. Box 513, 5600 MB Eindhoven, The Netherlands \\ OTB Solar B.V., P.O. Box 7108, 5605 JC, Eindhoven, The Netherlands
}

\begin{abstract}
The expanding thermal plasma (ETP) is a novel plasma technique currently used by several solar cell manufacturers for the deposition of silicon nitride antireflection coatings on (multi-) crystalline silicon solar cells. In this paper we will show that the ETP technique is versatile and can be used for the deposition of silicon nitride, silicon dioxide and hydrogenated amorphous silicon with a good level of surface passivation. In this way the ETP technique can meet the future PV demands with respect to the decrease in wafer thickness and the use of $n$-type material that requires good electrical and optical quality thin films at both the front and the back side of the solar cell.
\end{abstract}

\section{INTRODUCTION}

The current trends of decreasing solar cell wafer thickness and high desired conversion efficiencies put an increasing demand on the electrical and optical quality of the crystalline silicon wafer. Currently, both the optical and electrical properties at the front-side $n$-type emitter of the conventional $p$-type crystalline silicon solar cell are supplied by silicon nitride. However, the use of $n$-type base material and novel (high-efficiency) concepts will demand also a good level of passivation on highly doped $p$-type structures and an optimal reflection at the back of the solar cell. The level of surface passivation of silicon nitride on highly doped $p$-type silicon is rather poor and when silicon nitride is applied at the back of a conventional solar cell a floating junction is induced [1]. Both disadvantages are related to the relatively high positive built-in charge in the silicon nitride film. On the other hand, the best surface passivation on arbitrarily doped $\mathrm{c}-\mathrm{Si}$ is obtained by thermally grown oxide. The level of surface passivation of the as-grown oxide is rather poor, but is significantly improved by a subsequent anneal in a forming gas (10\% hydrogen in nitrogen). The best results are, however, obtained by a so-called alneal where the oxidation of a sacrificial high purity aluminum film supplies atomic hydrogen that passivates defect states at the interface between c-Si and thermal oxide. This elaborate processing in combination with the long required oxidation times at high temperatures to obtain a high quality thermal oxide films is expected not to be suitable for large-scale application for the production of future (high-efficiency) solar cells. For this reason there is ongoing search for new materials that can give the desired optical and electrical performance on crystalline silicon. Recently silicon carbide and amorphous silicon [2, 3] have shown a good level of surface passivation on $p$ - and $n$-type c-Si.

In this paper we will explore the surface passivation properties of silicon nitride, silicon dioxide and amorphous silicon deposited at a high rate by the expanding thermal plasma (ETP) technique. The ETP technique is currently already used by several solar cell manufactures for the deposition of their silicon nitride antireflection coating.

\section{THE EXPANDING THERMAL PLASMA}

The ETP technique is renowned for the high deposition rates that can be achieved for various materials including a-SiN $\mathrm{N}_{\mathrm{x}} \mathrm{H}[4,5]$. The reason that these high deposition rates can be achieved is due to the fact that plasma production takes place in an upstream plasma source operated at sub atmospheric pressure. At this high pressure, plasma production is very effective (with ionization degrees up to $10 \%$ and dissociation degrees up to $100 \%$ when molecular gases are used). This results in large flows of reactive ions and/or neutrals once the plasma expands into a downstream, low-pressure region. In this region, the large "amount of reactivity" can be used to dissociate large flows of deposition precursor gases. The downstream pressure is typically $20 \mathrm{~Pa}$ (comparable to other plasma techniques) and is sufficiently low to avoid heavy gas phase polymerization.

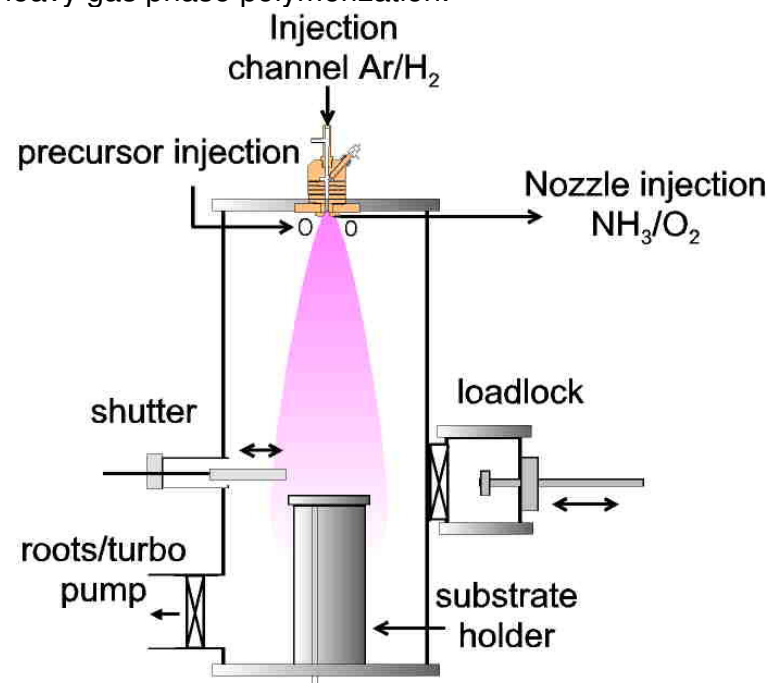

Figure 1: Schematic illustration of the expanding thermal plasma setup. At the right a detailed illustration of the expanding thermal plasma source is shown. 
The "remote" nature of the ETP technique allows for easier optimization of processing conditions and more freedom in reactor and substrate design and size. Finally, ion bombardment of the substrate is virtually absent as there is no electrical power coupling into the downstream plasma. Figure 1 shows schematic of typical lab-reactor with one ETP source. Precursor gasses can be injected at both the nozzle close to the plasma source and an injection ring in the plasma expansion. The ETP technique can be scaled-up by the use of multiple ETP sources to obtain a large area homogeneity and/or higher throughput [4].

\section{EXPERIMENT}

In this study silicon nitride, silicon dioxide and amorphous silicon were deposited by means of the ETP technique with the precursor gasses and their injection position summarized in Table 1.

Table 1: Precursors used for the deposition of silicon nitride, silicon dioxide and amorphous silicon by the ETP technique and their injection position.

\begin{tabular}{||l||l||l||l||}
\hline \hline Material & $\begin{array}{l}\text { Plasma } \\
\text { Source }\end{array}$ & $\begin{array}{l}\text { Nozzle } \\
\text { Injection }\end{array}$ & $\begin{array}{l}\text { Injection } \\
\text { ring }\end{array}$ \\
\hline \hline a-SiN ${ }_{\mathrm{x}}: \mathrm{H}$ & $\mathrm{Ar}$ & $\mathrm{NH}_{3}$ & $\mathrm{SiH}_{4}$ \\
\hline \hline $\mathrm{SiO}_{2}$ & $\mathrm{Ar}$ & $\mathrm{O}_{2}$ & $\mathrm{OMCTS}^{1}$ \\
\hline \hline $\mathrm{a}-\mathrm{Si}: \mathrm{H}$ & $\mathrm{Ar}-\mathrm{H}_{2}$ & - & $\mathrm{SiH}_{4}$ \\
\hline
\end{tabular}

Octamethyltetracyclosiloxane.

The level of surface passivation was tested on float-zone crystalline silicon substrates with various doping specs (as indicated in the figures). The substrates received a standard RCA1 and RCA2 cleaning with final HF-dip prior to deposition and a passivating film was deposited at both sides of the substrate. The effective lifetime of the coated substrates was measured by photoconductance decay method (Sinton WCT-100) both in transient and quasi-steady-state mode [6].

\section{SURFACE PASSIVATION BY ETP DEPOSITED FILMS}

\section{Silicon nitride}

Silicon nitride was the first material deposited by the ETP technique that was investigated for the application for the crystalline silicon solar cell. It was shown that silicon nitride could be deposited at deposition rates up to $20 \mathrm{~nm} / \mathrm{s}$ [5]. Initially the level of bulk and surface passivation lacked behind to high-quality silicon nitride used as a reference in the same study. The difference in the level of bulk passivation was attributed to a lower mass density of the silicon nitride films deposited by the ETP technique [7]. In the last few years the mass density of the silicon nitride films deposited by the ETP technique was significantly improved by changing the nitrogen containing precursor from $\mathrm{N}_{2}$ to $\mathrm{NH}_{3}$ and by elaborate process optimization [7, 8].

The level of surface passivation of high massdensity silicon nitride films was tested on the commercial DEPx system from OTB Solar B.V. [4]. All films were
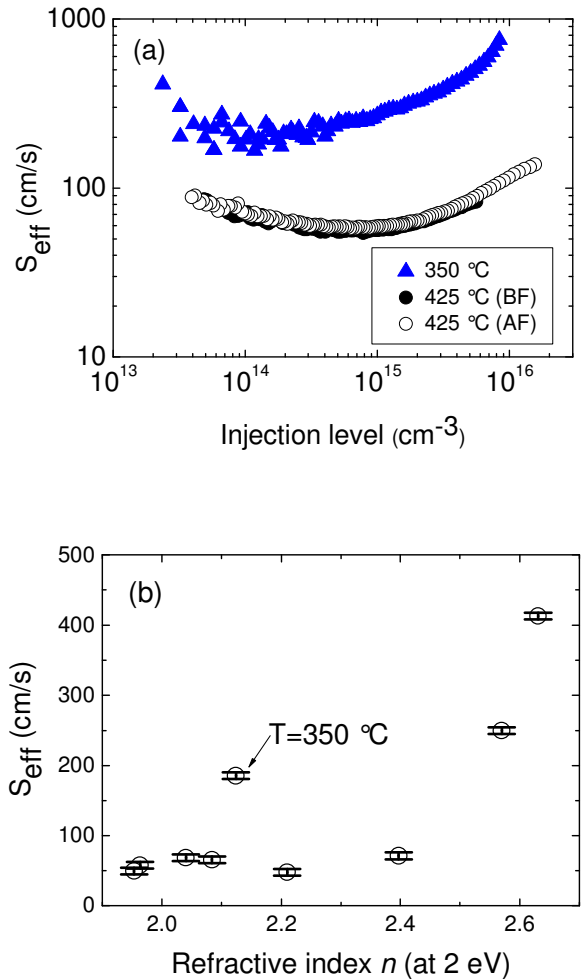

Figure 2: (a) Surface recombination velocity as a function of the injection level of a $8.4 \Omega \mathrm{cm} p$-type wafer coated with a silicon nitride film deposited at $350{ }^{\circ} \mathrm{C}$ and $425{ }^{\circ} \mathrm{C}$ before (BF) and after (AF) a standard industrial firing. (b) Surface recombination velocity on $8.4 \Omega \mathrm{cm} p$-type silicon as a function of the refractive index of the silicon nitride films deposited using the expanding thermal plasma technique [8].

deposited at rates $>4 \mathrm{~nm} / \mathrm{s}$ and the refractive index was altered by changing the silane flow rate. From Fig. 2 we can see that a good level of surface passivation is obtained for ETP deposited silicon nitride films for a broad refractive index range of 1.9-2.4. We can also see that the level of surface passivation is unaffected by a standard thermal firing process, indicating the thermal stability of the films. Similar to other deposition techniques we can see that the deposition temperature has a strong impact on the level of surface passivation. The obtained level of surface passivation for the widely applied refractive index of 2.1 is comparable to other industrially applied techniques [9].

\section{Silicon dioxide}

The biggest disadvantages of thermal oxide can be avoided by depositing a silicon dioxide film by means of plasma enhanced chemical vapor deposition. In this way the high process temperatures are avoided and the total processing time can significantly be reduced. For this reason already several groups worked on the development of plasma deposited silicon dioxide with a 


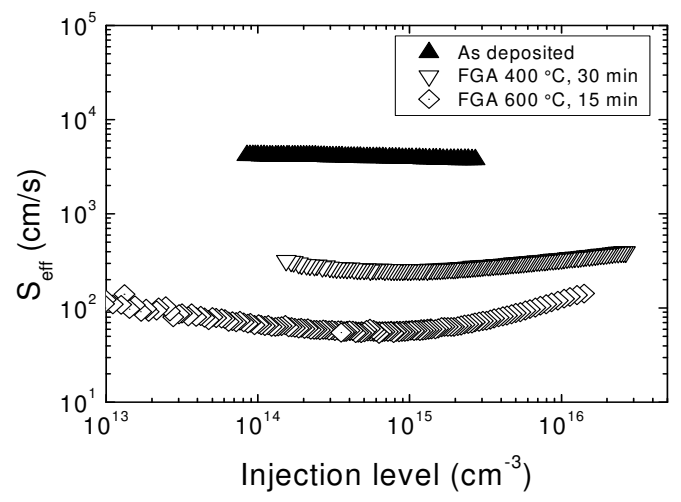

Figure 3: The surface passivation of silicon dioxide films deposited with the expanding thermal plasma technique using an $\mathrm{Ar}-\mathrm{O}_{2}$-octamethylcyclotetrasiloxane (OMCTS) mixture on $1.3 \Omega \mathrm{cm} n$-type wafers before and after forming gas anneals (FGA) as indicated in the figure.

good level of surface passivation (e.g. [10, 11]). However, so far the obtained level of surface passivation on low resistivity $p$ - and $n$-type wafers was only in the range of $400 \mathrm{~cm} / \mathrm{s}[10,11]$.

In this study we have deposited silicon dioxide films using the organosilicon OMCTS as the silicon containing precursor. In this way the use of silane can be avoided and no special safety installation is required. A detailed description of silicon dioxide deposition with the ETP technique will be treated in another contribution at this conference and will therefore only briefly discussed here [12].

Silicon dioxide films were deposited by the ETP technique from an argon-oxygen-OMCTS mixture in a labscale reactor. Silicon dioxide films with a low hydrogen content and a carbon content below 0.03 at.\% could be deposited at rates of $9 \mathrm{~nm} / \mathrm{s}$. As shown in Fig. 3, the asdeposited silicon dioxide like films show no significant level of surface passivation, comparable as reported before by other authors $[11,13]$. However, a 30 minute post-deposition anneal in forming gas $(10 \%$ hydrogen in nitrogen) already significantly improves the level of surface passivation to surface recombination velocity of $300 \mathrm{~cm} / \mathrm{s}$. The best results are obtained for a 15 minute forming gas anneal at $600{ }^{\circ} \mathrm{C}$, where a surface recombination velocity of $54 \mathrm{~cm} / \mathrm{s}$ is obtained. This is significantly lower compared to previously reported results on low resistivity $n$-type c-Si for films deposited from a $\mathrm{SiH}_{4}-\mathrm{O}_{2}$ mixture by other authors $[11,13]$.

\section{Amorphous silicon}

Hydrogenated amorphous silicon deposited by the ETP technique is already studied in great detail for the application in thin film solar cells [14]. Using the ETP technique with an $\mathrm{Ar}-\mathrm{H}_{2}-\mathrm{SiH}_{4}$ mixture, it was shown that device quality material could be deposited at a deposition rate of $10 \mathrm{~nm} / \mathrm{s}$ [14]. Recently, amorphous silicon has also attracted interest from the crystalline silicon solar cell community due to its excellent surface passivation on

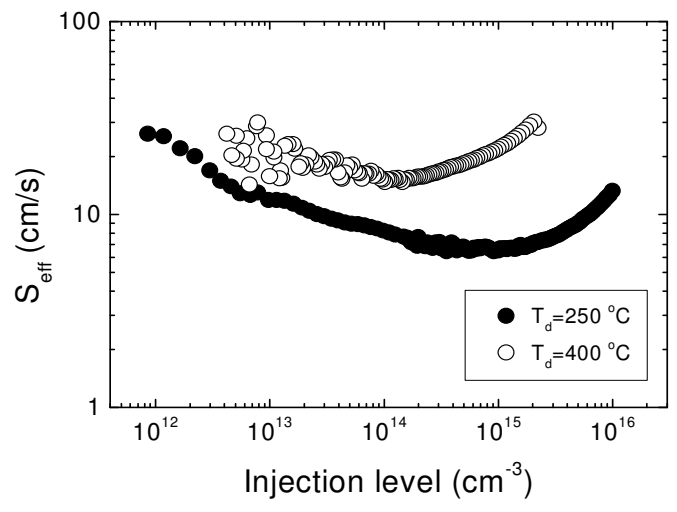

Figure 4: The surface passivation of amorphous silicon deposited using the expanding thermal plasma technique as obtained for the indicated deposition temperatures on $1.9 \Omega \mathrm{cm} n$-type crystalline silicon wafers.

crystalline silicon. This is effectively used in the heterojunction solar cell or as a back surface passivation film in a more conventional solar cell design [15, 16].

In Fig. 4 the level of surface passivation is shown for an amorphous silicon film deposited by the ETP technique at $250{ }^{\circ} \mathrm{C}$ at a deposition rate of $1 \mathrm{~nm} / \mathrm{s}$. The level of surface passivation on low resistivity $n$-type silicon is comparable to results obtained by Dauwe et al. [2]. Even at $400{ }^{\circ} \mathrm{C}$, amorphous silicon films with an excellent level of surface passivation can be deposited by the ETP technique as shown in Fig. 4 at deposition rates of $\sim 1.5$ $\mathrm{nm} / \mathrm{s}$, what was not possible before by rf-PECVD [2].

\section{CONCLUSIONS}

We have shown that various materials deposited at a high rate by the ETP technique provide a good level of surface passivation on crystalline silicon as summarized in Table 2. Hence, apart from its current application for the deposition of the silicon nitride antireflection coating, the ETP technique can provide the solution put forward to meet the requirements for the future (high-efficiency) solar cells.

Table 2: Overview of the surface recombination velocities (SRV) for the various ETP deposited materials

\begin{tabular}{|l||l||l||l||}
\hline Material & $\begin{array}{l}\text { Deposition } \\
\text { rate }(\mathrm{nm} / \mathrm{s})\end{array}$ & Wafer type & $\begin{array}{l}\text { SRV } \\
(\mathrm{cm} / \mathrm{s})\end{array}$ \\
\hline \hline a-SiN $\mathrm{x}: \mathrm{H}$ & $>4$ & $\begin{array}{l}8.3 \Omega \mathrm{cm} \\
p \text {-type }\end{array}$ & $50-60$ \\
& & $\begin{array}{l}1.3 \Omega \mathrm{cm} \\
n \text {-type }\end{array}$ & $54^{1}$ \\
\hline \hline $\mathrm{SiO}_{2}$ & 9 & $\begin{array}{l}1.9 \Omega \mathrm{cm} \\
n \text {-type }\end{array}$ & $\begin{array}{l}7^{2} \\
15^{3}\end{array}$ \\
\hline \hline a-Si:H & 1 & \\
\hline
\end{tabular}

${ }^{1}$ After a 15 minute forming gas anneal at $600{ }^{\circ} \mathrm{C}$.

${ }^{2}$ Deposition temperature $250^{\circ} \mathrm{C}$.

${ }^{3}$ Deposition temperature $400{ }^{\circ} \mathrm{C}$. 


\section{ACKNOWLEDGEMENTS}

M.J.F. van de Sande and J.F.C. Jansen are thanked for their skillful technical assistance. This study has been carried out within the E.E.T. "HR-CEL" program funded by the Netherlands Ministry of Economic Affairs, the Ministry of Education, Culture and Science and the Ministry of Public Housing, Physical planning and Environment. The research of W.K. is made possible by a fellowship of the Royal Netherlands Academy of Arts and Sciences (KNAW).

\section{REFERENCES}

1. Dauwe, S., L. Mittelstadt, A. Metz, and R. Hezel, "Experimental evidence of parasitic shunting in silicon nitride rear surface passivated solar cells", Progress in Photovoltaics, 10, 2002, pp. 271.

2. Dauwe, S., J. Schmidt, and R. Hezel. "Very low surface recombination velocities on $p$ - and $n$-type silicon wafers passivated with hydrogenated amorphous silicon films". 29th IEEE Photovoltaic Specialist Conference. 2002. New Orleans, 1246.

3. Martin, I., M. Vetter, A. Orpella, J. Puigdollers, A. Cuevas, and R. Alcubilla, "Surface passivation of p-type crystalline $\mathrm{Si}$ by plasma enhanced chemical vapor deposited amorphous SiCx : H films", Applied Physics Letters, 79, 2001, pp. 2199.

4. Bosch, R.C.M., W.T.M. Stals, A.J.M. Van Erven, R.L.J.R. Pennings, and M.D. Bijker. "HighThroughput PECVD Production Tool for In-Line Silicon-Nitride Deposition on Silicon Solar Cells". 19th European Photovoltaic Solar Energy Conference. 2004. Paris, 1098.

5. Kessels, W.M.M., J. Hong, F.J.H. van Assche, J.D. Moschner, T. Lauinger, W.J. Soppe, A.W. Weeber, D.C. Schram, and M.C.M. van de Sanden, "High-rate deposition of a-SiNx : H for photovoltaic applications by the expanding thermal plasma", Journal of Vacuum Science \& Technology A 20, 2002, pp. 1704.

6. Sinton, R.A. and A. Cuevas, "Contactless determination of current-voltage characteristics and minority-carrier lifetimes in semiconductors from quasi-steady-state photoconductance data", Applied Physics Letters, 69, 1996, pp. 2510.

7. Hong, J., W.M.M. Kessels, W.J. Soppe, A.W. Weeber, W.M. Arnoldbik, and M.C.M. van de Sanden, "Influence of the high-temperature "firing" step on high-rate plasma deposited silicon nitride films used as bulk passivating antireflection coatings on silicon solar cells", Journal of Vacuum Science \& Technology B, 21, 2003, pp. 2123.

8. Hoex, B., A.J.M. van Erven, R.C.M. Bosch, W.T.M. Stals, M.D. Bijker, P.J. van den Oever, W.M.M. Kessels, and M.C.M. van de Sanden, "Industrial high-rate $(\sim 5 \mathrm{~nm} / \mathrm{s})$ deposited silicon nitride yielding high-quality bulk and surface passivation under optimum anti-reflection coating conditions", Progress in Photovoltaics, 13, 2005, pp. 705.

9. Moschner, J.D., J. Henze, J. Schmidt, and R. Hezel, "High-quality surface passivation of silicon solar cells in an industrial-type inline plasma silicon nitride deposition system", Progress in Photovoltaics, 12, 2004, pp. 21-31.

10. Ebong, A., P. Doshi, S. Narasimha, A. Rohatgi, J. Wang, and M.A. El-Sayed, "The effect of low and high temperature anneals on the hydrogen content and passivation of Si surface coated with $\mathrm{SiO} 2$ and SiN films", Journal of the Electrochemical Society, 146, 1999, pp. 1921.

11. Leguijt, C., P. Lolgen, J.A. Eikelboom, A.W. Weeber, F.M. Schuurmans, W.C. Sinke, P.F.A. Alkemade, P.M. Sarro, C.H.M. Maree, and L.A. Verhoef, "Low temperature surface passivation for silicon solar cells", Solar Energy Materials and Solar Cells, 40, 1996, pp. 297.

12. Hoex, B., F.J.J. Peeters, M. Creatore, M.D. Bijker, W.M.M. Kessels, and M.C.M. van de Sanden. "Excellent surface passivation of c-Si by high rate plasma deposited silicon oxide". this conference. 2006,

13. Sivoththaman, S., P. De Schepper, W. Laureys, J.F. Nijs, and R.P. Mertens, "Improving lowtemperature APCVD $\mathrm{SiO} 2$ passivation by rapid thermal annealing for Si devices", IEEE Electron Device Letters, 19, 1998, pp. 505.

14. Kessels, W.M.M., R.J. Severens, A.H.M. Smets, B.A. Korevaar, G.J. Adriaenssens, D.C. Schram, and M.C.M. van de Sanden, "Hydrogenated amorphous silicon deposited at very high growth rates by an expanding $\mathrm{Ar}-\mathrm{H}-2-\mathrm{SiH} 4$ plasma", Journal of Applied Physics, 89, 2001, pp. 2404.

15. Schaper, M., J. Schmidt, H. Plagwitz, and R. Brendel, "20.1\%-efficient crystalline silicon solar cell with amorphous silicon rear-surface passivation", Progress in Photovoltaics, 13, 2005, pp. 381.

16. Taguchi, M., K. Kawamoto, S. Tsuge, T. Baba, H. Sakata, M. Morizane, K. Uchihashi, N. Nakamura, S. Kiyama, and O. Oota, "HIT (TM) cells - High-efficiency crystalline Si cells with novel structure", Progress in Photovoltaics, 8, 2000, pp. 503. 